\title{
The potential role of feature tracking in adult congenital heart disease: advantages and disadvantages in measuring myocardial deformation by cardiovascular magnetic resonance
}

\author{
Ahmed M. Dardeer ${ }^{1,2,3}$, Lucy Hudsmith', Roman Wesolowski ${ }^{1}$, Paul Clift ${ }^{1}$ and Richard P. Steeds ${ }^{1,2^{*}}$
}

\begin{abstract}
Background: Cardiac magnetic resonance (CMR) imaging has several advantages over other imaging modalities in adult patients with congenital heart disease. Limitations remain however, in the assessment of myocardial function based on volumetric methods. There is increasing evidence in a range of diseases that myocardial strain is a more sensitive measure of regional and global ventricular contractile function.

Main body: Feature tracking (FT), is a CMR-based method that measures strain without the need for additional sequence acquisition which can be analyzed rapidly, opening the possibility of use in adult congenital heart disease (ACHD). The aim of this review is to outline the technique of FT-CMR, its advantages and disadvantages compared to other techniques, review the values obtained, and to outline the preliminary data in support of its use in ACHD. In short, FT is a semi-automated post-processing technique that can be performed on routinely acquired images and thereby does not prolong scan time, is reproducible and not overly time-consuming. Although FT-CMR promises much, inevitably there remain limitations. While FT has excellent spatial resolution, temporal resolution is sub-optimal relative to speckle tracking echocardiography.

Conclusion: FT-CMR is an emerging technique of measuring the myocardial strain that is comparable to speckle tracking echocardiography and the gold standard myocardial tagging CMR. FT-CMR derived strain parameters have potential diagnostic, risk stratification and prognostic value in the growing ACHD population.
\end{abstract}

Keywords: Cardiac magnetic resonance, Feature tracking, Adult congenital heart disease

\section{Background}

Patients with adult congenital heart disease (ACHD) are an ever-growing population which require long-term and frequently lifelong, follow-up. Investigations used to identify progression of existing disease, complications from previous surgery and new symptoms must deliver good quality information at low risk to the patient, with high reproducibility when used repeatedly over time.

\footnotetext{
*Correspondence: Rick.steeds@uhb.nhs.uk

'Department of Cardiology, Queen Elizabeth Hospital, University Hospital Birmingham, Birmingham, UK

${ }^{2}$ Institute of Cardiovascular Sciences, University of Birmingham, Birmingham UK

Full list of author information is available at the end of the article
}

Cardiovascular magnetic resonance (CMR) imaging has a number of advantages over other imaging modalities, including high resolution imaging without limitation by acoustic window, low risk to the patient, and reproducible measurement of left-sided volumes and ejection fraction [1]. Although well established, issues remain in routine clinical practice. Firstly, repeatable measurements of right ventricular size and function by CMR can be time consuming, difficult to achieve, require dedicated software and a meticulous and clearly defined technique [2]. Secondly, while left (LV) and right ventricular ejection fraction (EF) are common markers of systolic function that carry prognostic weight, these lack

(c) The Author(s). 2018 Open Access This article is distributed under the terms of the Creative Commons Attribution 4.0 International License (http://creativecommons.org/licenses/by/4.0/), which permits unrestricted use, distribution, and 
sensitivity and appear to be late indicators of pump failure, particularly in ACHD where co-existing lesions that alter loading conditions are common [3].

There is increasing evidence in the general adult population that myocardial deformation is a more sensitive, quantitative evaluation of global contractile function that can detect changes in ventricular function before a fall in EF [3]. Moreover, myocardial deformation (strain, torsion and dyssynchrony) can also deliver quantitative evaluation of regional function. The most frequently used index is strain, which measures the percent change in myocardial length from a resting state to one after application of stress or force. Echocardiography derived strain has been shown in multiple studies to deliver incremental prognostic benefit to clinical assessment and to EF both in community and hospitalbased populations [4]. Much of the evidence relating to measurement of strain in adult congenital heart disease (ACHD) has been derived from echocardiography and hitherto, the role of CMR has been limited, as this previously required the acquisition of additional 'tagging' sequences and time-consuming analysis. The development of feature tracking CMR (FT-CMR), has allowed measurement of deformation using standard steady state free precession (SSFP) cine sequences which are standard in most protocols in ACHD [1]. Moreover, the results can be analyzed quickly in a semi-automated fashion using a number of software systems, including Diogenes and Cardiac Performance Analysis MRsoftware (TomTec, Germany), Toshiba (Tokyo, Japan) and Circle CVi42 (Calgary, Canada). The aim of this review is to outline the basic principles of FT-CMR, its advantages and disadvantages compared to other techniques, and to outline the potential clinical applications in ACHD.

\section{The technique of feature-tracking CMR}

FT-CMR is based on optical flow technology and tracks different elements at the boundary between the cavity and myocardium, using a maximum likelihood methodology that measures displacement of a peculiar pattern in an initial image (for example, the endocardial border) and then recognizes this pattern within a second image taken moments later. There are a number of steps to produce the required data. The first step is to ensure that good quality SSFP cines are acquired, with attention to end-expiratory breath-holding and a stable cardiac rhythm that is gated accurately over a high number of phases (25). Following acquisition, either the endocardial or endocardial and epicardial borders are traced in the frame with the greatest clarity between cavity and myocardium, usually end-diastole, with exclusion of the papillary muscles and the trabeculae [5]. The automated software algorithm is then activated and starts by tracking a feature in 1-dimension over one cardiac cycle in a direction orthogonal to the border (detecting motion inwards and outwards like an M-mode) and then in 2-dimensions using a search window frame by frame (See Figs. 1 and 2). The features tracked on CMR are those of different signal intensity at the border between myocardium and blood pool, rather than the motion of individual pixels or group of pixels as is done on echocardiography. In a long axis view, the longitudinal displacement of the atrioventricular junction is first detected, followed by the entire border from base to apex according to the motion of the AV junction. The algorithm is hierarchical, in that the 2-dimension search window is then reduced and becomes smaller at each step (at least $8 \times 8$ pixels.) [6]. The technical steps involved in 2D FT-CMR help to explain the difference in the results from 2D speckle tracking echocardiography (STE), which relate in part to which region of the myocardium is tracked. 2D STE tracks the speckles within the myocardium itself; however, 2D FT-CMR tracks the endocardial and epicardial borders but cannot distinguish features within the compact myocardium [6]. Strain in each direction is then calculated by the change in distance between points, and strain rate based on rate of change in distance [See attached Additional files 1, 2 and 3].

\section{Advantages and disadvantages of FT-CMR}

The advantage of SSFP cine imaging compared to 2D and 3D echocardiography - and thereby the advantage of FT-CMR over STE - is that it provides an excellent contrast between blood pool and the myocardium and produces good image quality more reliably without limitation by acoustic window [7]. This is particularly important in congenital heart disease patients, many of whom have had multiple previous surgeries and scars with Goretex membrane or chest deformities leading to difficult windows. For example, in a study of 15 adult Fontan (single ventricle) patients at least one myocardial segment could not be assessed by STE in 63\% of the cohort, although all segments could be assesssed by FTCMR [8]. The major advantage of FT-CMR over tagging CMR methods for analysis of deformation, such as spatial modulation of magnetization (SPAMM) and the complementary SPAMM (C-SPAMM), is that no additional sequences are required see Fig. 3. Moreover, these sequences have been hampered by the gradual disappearance of the tags with time, reducing the ability to analyse diastolic parameters [9]. Although tagging is considered the gold standard noninvasive imaging technique for strain quantification and has been validated against sonomicrometry in humans [10] and nonhomogenous strain phantoms [11], a huge volume of data is created that is time-consuming to analyze, so it has failed to enter routine clinical usage. 

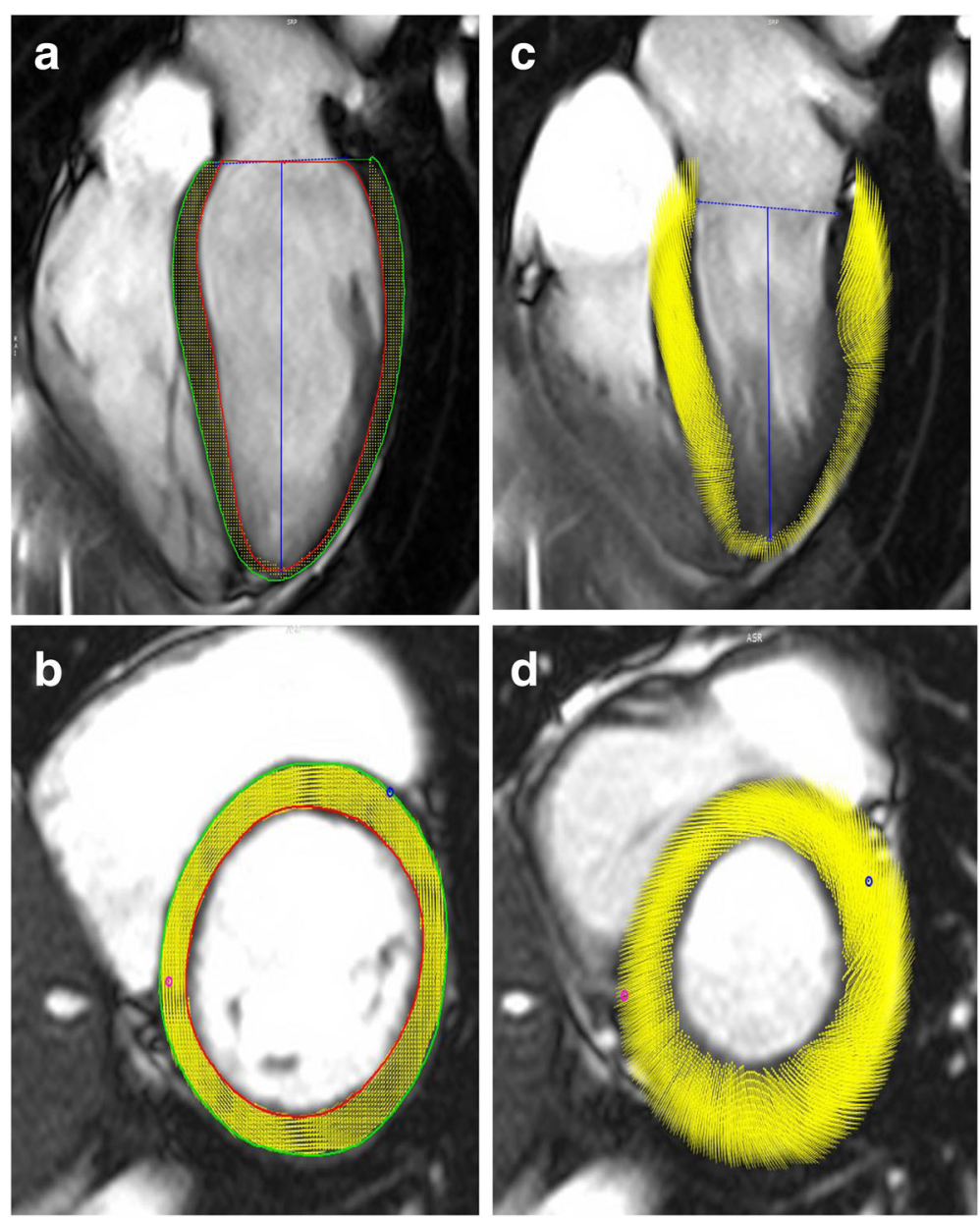

Fig. 1 LV FT-CMR using Circle CVi42. The LV endocardial and epicardial borders are manually traced at end-diastole in the long axis (a) and short axis (b) then the software tracks the features to end-systole in the long axis (c) and short axis (d)

The main limitation of FT-CMR is that, while FT has excellent spatial resolution, temporal resolution is dependent on heart rate and is lower than the temporal resolution of 2D STE [12] (Table 1). Temporal averaging with FT-CMR means that strain values tend to be lower than STE and limits the application where cardiac rhythm is irregular or if there are beat-to-beat differences in image stability and quality. All tracking techniques, whether STE or FT-CMR (2D or 3D), are more robust when studying global compared to regional contractile function [13]. Furthermore, all 2D techniques share a susceptibility to through plane motion, when a feature cannot be tracked as it moves out of the image slice. 3D FT-CMR can potentially overcome this but as these methods currently rely on a short axis stack, the resolution may be even worse in the through-plane long axis, depending on the number of images acquired in this plane [9]. As a general rule in feature-tracking, integral variables, such as displacement and strain, are more reliable than differential ones, including velocity and strain rate. In particular, temporal resolution is such that rapid myocardial events such as isovolumic time intervals are not reliable.

One of the potential advantages of FT-CMR in the ACHD population is that this can also deliver quantification of myocardial deformation in the right ventricle and right atrium without limitation by acoustic window. Assessment of right ventricular performance is key for the follow up of many ACHD conditions such as Tetralogy of Fallot and those conditions with an RV-PA conduit. Although STE is increasingly used in ACHD and has excellent feasibility and reproducibility in the assessment of RV strain in healthy individuals [14], this is not always the case in patients with complex congenital disease. For example, patients with univentricular hearts and systemic right ventricles have been excluded from studies at major ACHD centers due to difficulties in acquisition and standardization of analysis [15]. Therefore FT-CMR may provide further insights into potential markers for arrhythmias, exercise limitation as well as morbidity and 

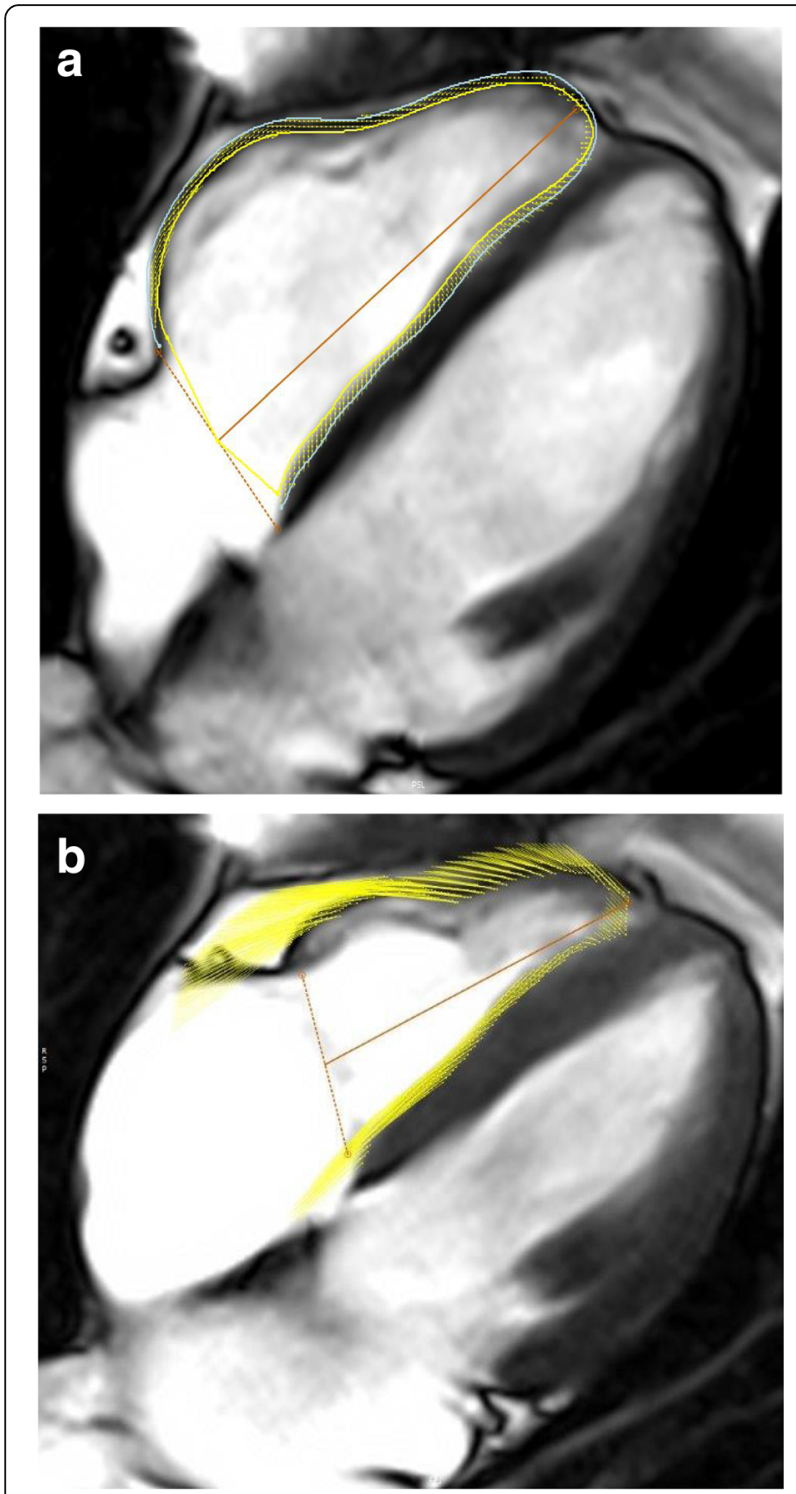

Fig. 2 RV FT-CMR using Circle CVi42. The RV endocardial and epicardial borders are manually traced at end-diastole in the long axis (a) then the software tracks the features to end-systole (b)

mortality, although further work is needed. Table 2 outlines the normal ranges for these.

\section{Feature-tracking CMR: Validation and comparison to other techniques}

FT-CMR has been validated against artificially-prepared phantom images with minimal error from theoretical values for strain and strain rate [16], although the technique has yet to be validated against the clinical gold standard sonomicrometry (a technique that involves measurement of the speed of acoustic signals between crystals embedded in the tissue under study and which is highly invasive).
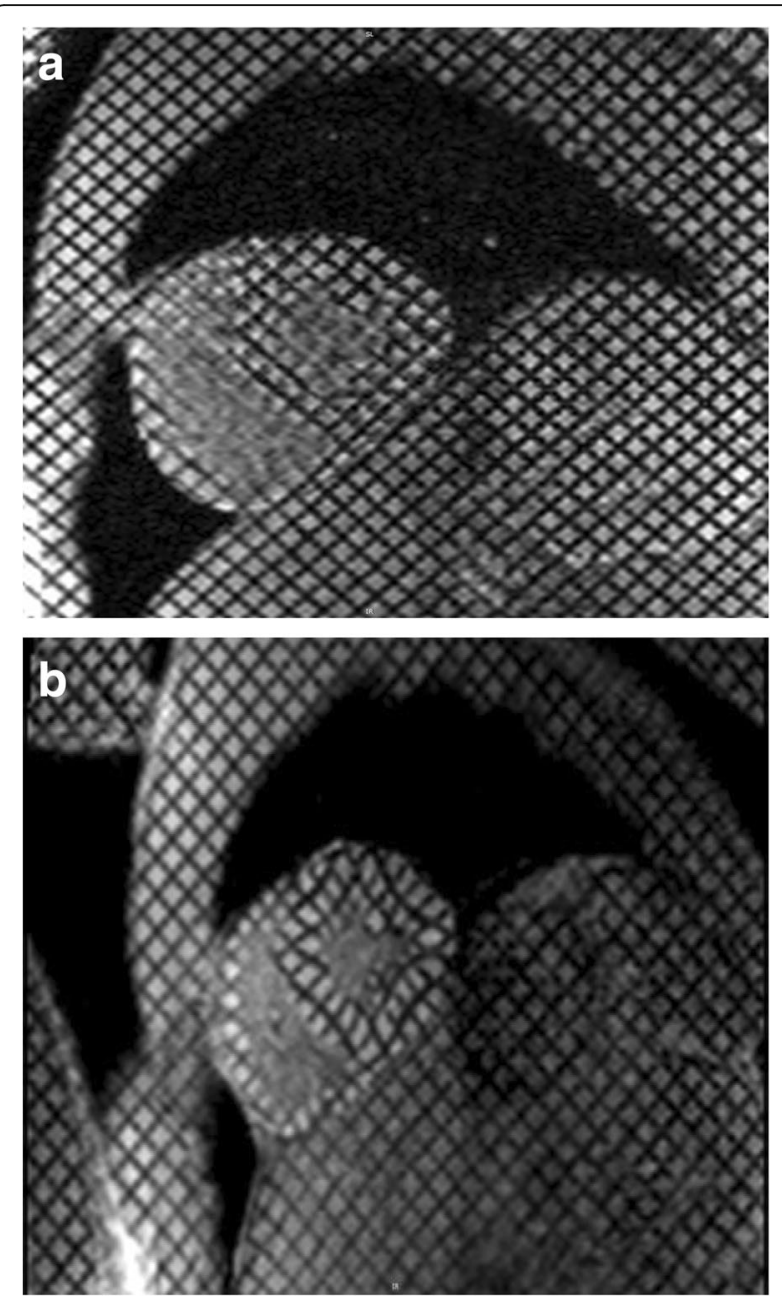

Fig. 3 Myocardial Tagging. Short axis tagging at the basal left ventricular level. Note that the tags relax with ventricular diastole (a) and follow the myocardial deformation in systole (b)

\section{FT-CMR and tagging}

FT-CMR has been validated against tagged harmonic phase analysis (HARP) in 191 subjects with Duchenne muscular dystrophy suffering from a range of cardiac dysfunction for peak circumferential strain $(-12.16 \pm 3.12 \%$ vs $-12.52 \pm 2.69 \%, r=0.899$ ) [17]. Agreement between FT-CMR and tagging however, is not perfect. In general, results for FT-CMR are more reliable for circumferential and longitudinal strain than for radial strain, which is thought to be due to the need to track tissue interfaces for radial strain as opposed to the cavitymyocardial interface. For example, in a study comparing FT-CMR with tagged SPAMM, Moody et al. found good agreement in calculating peak global circumferential strain $(-22.7 \pm 6.2 \%$ vs. $-22.5 \pm 6.9 \%$, bias $0.2 \pm 4.0 \%)$ and peak global longitudinal strain $(-18.1 \pm 5.0 \%$ vs. $-16.7 \pm 4.8 \%$, bias $1.3 \pm 3.8 \%$ ) but poor agreement for radial strain [18]. 
Table 1 Comparison between different imaging modalities that assess strain

\begin{tabular}{|c|c|c|c|}
\hline & FT-CMR & Myocardial tagging & Speckle tracking Echo \\
\hline Advantages & $\begin{array}{l}\text { Unrestricted by acoustic window } \\
\text { Employs existing cine imaging } \\
\text { Rapid semi-automated analysis }\end{array}$ & $\begin{array}{l}\text { Unaffected by through } \\
\text { plane motion. }\end{array}$ & $\begin{array}{l}\text { Widely available } \\
\text { Low cost } \\
\text { Rapid acquisition } \\
\text { Rapid semi-automated analysis } \\
\text { High temporal resolution }\end{array}$ \\
\hline Limitations & $\begin{array}{l}\text { Temporal resolution } \\
\text { Intervendor variability } \\
\text { Through plane motion } \\
\text { Dependent on access to CMR } \\
\text { Requires breath-hold cines } \\
\text { Arrhythmia }\end{array}$ & $\begin{array}{l}\text { Temporal resolution } \\
\text { Tags fade in diastole } \\
\text { Need for acquisition of additional } \\
\text { sequences } \\
\text { Limited availability } \\
\text { Requires breath-hold } \\
\text { Complex, time-consuming analysis } \\
\text { with dedicated software }\end{array}$ & $\begin{array}{l}\text { Acoustic window } \\
\text { Intervendor variability } \\
\text { Through plane motion } \\
\text { (3D then affected by temporal } \\
\text { resolution) }\end{array}$ \\
\hline Frame rate & Lower & Lower & Higher \\
\hline Temporal resolution & HR dependent (if HR is 60 , it is $30-40 \mathrm{~ms}$ ). & $35 \mathrm{~ms}$. & $12.5-25 \mathrm{~ms}$. \\
\hline Spatial resolution & $1-2 \times 1-2 \mathrm{~mm}$ in plane resolution. & $1-2 \times 2-3 \mathrm{~mm}$ in plane resolution. & Pixel size is about $0.3 \mathrm{~mm}$. \\
\hline
\end{tabular}

\section{FT-CMR and STE}

Likewise, inter-modality agreement between FT-CMR and STE is closest for global longitudinal strain (GLS), then global circumferential strain (GCS) and worst for global radial strain (GRS), with lower values obtained by FT-CMR for the latter two parameters. For example, Obotaka studied 106 patients who completed FT-CMR and both 2D and 3D STE on the same day, obtaining similar results for GLS ( $r=0.83$ for 2D STE; 0.87 for 3D STE) with the limits of agreement (LOA) ranging from \pm 3.6 to $\pm 4.9 \%$. Similar results were obtained for GCS $(r=0.90$ for 2D STE; 0.88 for 3D STE) with LOA $\pm 6.8-8.5 \%$. The correlations for GRS were significantly worse ( $r=0.69$ for 2D STE; 0.82 for 3D STE) with wide LOA ranging from \pm 12.4 to $\pm 16.3 \%$ [7]. This study replicated findings from others that FT-CMR can be measured succesfully in almost all patients (98\%) [19], which is particularly important in the ACHD population where adequate image quality for reliable analysis of myocardial deformation may be more difficult to obtain by echocardiography.

\section{Reproducibility}

A major issue for quantifying myocardial function in ACHD is that intra-modality reproducibility must be high, so that clinicians can depend on differences in results between annual scans as reflecting pathophysiological change. Ghelani et al. compared the results from 134 paired studies of functional single ventricles in the Fontan circulation performed less than 1 year apart, 60 with dominant right and 74 with dominant left ventricles. Intra- modality inter-observer agreement for FTCMR was similar to STE (FT-CMR GCS Rc $=0.94$ vs STE Rc $=0.84$; FT-CMR GLS Rc $=0.75$ vs STE 0.79), with similar correlations for intra-modality intra-observer measurements [20].

In summary, FT-CMR has high feasibility, good reproducibility for GCS and GLS but less optimal results for GRS, and there may be differences in results between modalities that mean long-term assessment of ACHD patients should consistently use one technique for serial follow-up. It is also important to note that there are also likely to be differences in results according to the

Table 2 Normal ranges for right ventricle and right atrial global longitudinal strain

\begin{tabular}{lllllll}
\hline Reference & Vendor Software & Controls studied (n) & Age (years) & RV FWGLS & RV FW +S & RA GLS \\
\hline Kutty et al. 2017 [32] & TomTec & 140 & $16.4 \pm 11$ & NR & $-18.5 \pm 5.3$ & $-27.1 \pm 1$ \\
Liu et al. 2017 [33] & Circle CVi42 & 100 & $45 \pm 14.3$ & $-24.2 \pm 3.59$ & $-21.9 \pm 3.24$ & $-21.1 \pm 3.76$ \\
Truong et al. 2017 [34] & CircleCVi42 & 50 & $32(15-56)$ & $-22.11 \pm 3.51$ & NR & NR \\
Heiberg et al. 2015 [35] & TomTec & 28 & $21.3 \pm 2.5$ & NR & $-21 \pm 4.7$ & NR \\
Kempny et al. 2012 [27] & TomTec & 25 & $33.1 \pm 15.7$ & NR & $-24.1 \pm 4$ & NR \\
Padiyath et al. [36] & TomTec & 20 & $37 \pm 8.5$ & NR & $-19.9 \pm 4.0$ & NR \\
Augustine et al. 2012 [37] & TomTec & 19 & NR & $-21.1 \pm 2.1$ & NR N N & $-23.8 \pm 9.9$ \\
Morton et al. 2012 [38] & TomTec & 16 & $27.9 \pm 5.7$ & NR & NR \\
\hline
\end{tabular}

$R V$ right ventricle, FWGLS free wall global longitudinal strain, $F W+S$ free wall plus septum, $R A$ right atrium, $N R$ not reported 
software used for calculation of FT-CMR, similar to the issues that bedevilled STE [5]. Table 3 demonstrates differences in the normal ranges for 2D FT-CMR for GLS, GCS and GRS for the LV between different software manufacturers.

\section{Value of feature tracking CMR in adult congenital heart disease}

The number of adults with congenital heart disease has significantly increased and now outnumbers the tally of paediatric cardiology patients [21]. The median survival of ACHD patients has shifted from the neonatal period to reflect that of the general population [22]. The major focal point of serial imaging has also shifted, with emphasis on arrhythmia, sudden cardiac death and overall prognosis, early detection of ventricular dysfunction and correlation with reduction in exercise capacity. The number of publications in these areas using FT-CMR has accelerated, and currently published studies in ACHD are summarized in Table 4. The most important of these are summarized in more detail under the following areas:

\section{Prediction of arrhythmia, sudden cardiac death and overall mortality}

Patients with repaired tetralogy of Fallot (ToF) develop right and left ventricular dysfunction and may be at high risk of adverse outcomes including sudden cardiac death. Risk stratification for these patients is challenging $[22,23]$ but FT-CMR may be helpful. Two preliminary, small studies of patients following early repair of ToF suggested that the maximum time to peak circumferential strain in the LV [24] and impaired GLS and GCS of both the LV and RV were strongly associated with death and sustained ventricular tachycardia [24, 25]. These findings were then confirmed in a larger prospective, multicenter study of 372 patients with repaired ToF by Orwat et al. [26], with reduced LV and RV GLS predicting the coprimary outcome of death, successful resuscitation or ventricular tachycardia.

\section{Correlation with a reduction in exercise capacity}

In a number of studies across a range of adults with differing congenital heart diseases, a consistent association has been found between impaired strain and reduced exercise capacity on formal testing. Schmidt et al. [8] investigated both STE and FT-CMR in a small group of adult Fontan patients ( $n=15$ STE and 13 FT-CMR, mean age $27 \pm 7$ years) and found an association between impaired systemic ventricular GLS \& GCS and NYHA status and peak oxygen uptake ( $r=0.71$ and $p=0.046$ for GLS). Similarly, Kempny et al. [27] found that FT-CMR RV strain was related to exercise capacity in a population of 28 repaired Tetralogy of Fallot patients (mean age $40 \pm 13$ years), with correlation between peak oxygen uptake and RV radial strain $(r=0.49, p=0.02)$ and VE/ $\mathrm{VCO}_{2}$ slope with RV GRS and GCS $(r=-0.54, p=0.01$, and $r=-0.56, p=0.008$, respectively). In a larger study of 91 adult patients (mean age $30 \pm 5.1$ years) following atrial repair of transposition of the great arteries (TGA), Tutarel et al. [28] found that LV GLS again correlated with peak $\mathrm{VO}_{2}(r=-0.4, p<0.001)$. A long term aim of noninvasive imaging has been the ability to predict onset of symptoms in those cardiovascular diseases where this is a trigger for intervention and in this respect, LV and RV FTCMR offers some hope.

\section{Detection of impaired ventricular function}

Impaired systolic ventricular function is also a common trigger for intervention but awaiting fall in ejection fraction often results in worse outcome. Several studies, thereby reflecting the results of STE strain in many other common cardiovascular conditions, have found that altered deformation on FT-CMR is a sensitive measure of myocardial function in ACHD that can detect change in contractility before fall in EF. For

Table 3 Differences in the normal ranges for 2D FT-CMR for Global circumferential, longitudinal and radial peak strains for the LV between different software manufacturers

\begin{tabular}{|c|c|c|c|c|c|c|}
\hline \multirow[t]{2}{*}{ Reference } & \multirow[t]{2}{*}{ Vendor software } & \multirow[t]{2}{*}{ Controls (n) } & \multirow[t]{2}{*}{ Age (years) } & \multicolumn{3}{|l|}{$2 \mathrm{D}$} \\
\hline & & & & GCS & GLS & GRS \\
\hline Andre et al. 2015 [39] & TomTec & 150 & $45.8 \pm 14$ & $-21.3 \pm 3.3$ & $-21.6 \pm 3.2$ & $36.3 \pm 8.7$ \\
\hline Augustine et al. 2013 [40] & TomTec & 145 & $29.7 \pm 7.6$ & $-21 \pm 3$ & $-19 \pm 3$ & $25 \pm 6$ \\
\hline Liu et al. 2017 [13] & CircleCVi42 & 100 & $45 \pm 14.3$ & $-20.9 \pm 3.7$ & $-19.8 \pm 2.9$ & $47.6 \pm 15.4$ \\
\hline Taylor et al. 2015 [41] & TomTec & 100 & $44.5 \pm 14$ & $-18 . \pm 2.9$ & $-19.1 \pm 4.1$ & $39.8 \pm 8.3$ \\
\hline Heiberg et al. 2015 [35] & TomTec & 28 & $21.3 \pm 2.5$ & $-24.7 \pm 3.1$ & $-18 \pm 2.85$ & $64.5 \pm 9.89$ \\
\hline Kempny et al. 2012 [27] & TomTec & 25 & $33.1 \pm 15.7$ & $-23.5 \pm 6.0$ & $-21.3 \pm 3.3$ & $28.0 \pm 11.3$ \\
\hline Padiyath et al. 2013 [36] & TomTec & 20 & $37 \pm 8.5$ & $-24.6 \pm 2.5$ & $-19.9 \pm 5.1$ & $50.9 \pm 12.4$ \\
\hline Morton et al. 2012 [38] & TomTec & 16 & $27.9 \pm 5.7$ & $-17.6 \pm 5.0$ & $-21.0 \pm 5.1$ & $22.6 \pm 7.9$ \\
\hline
\end{tabular}




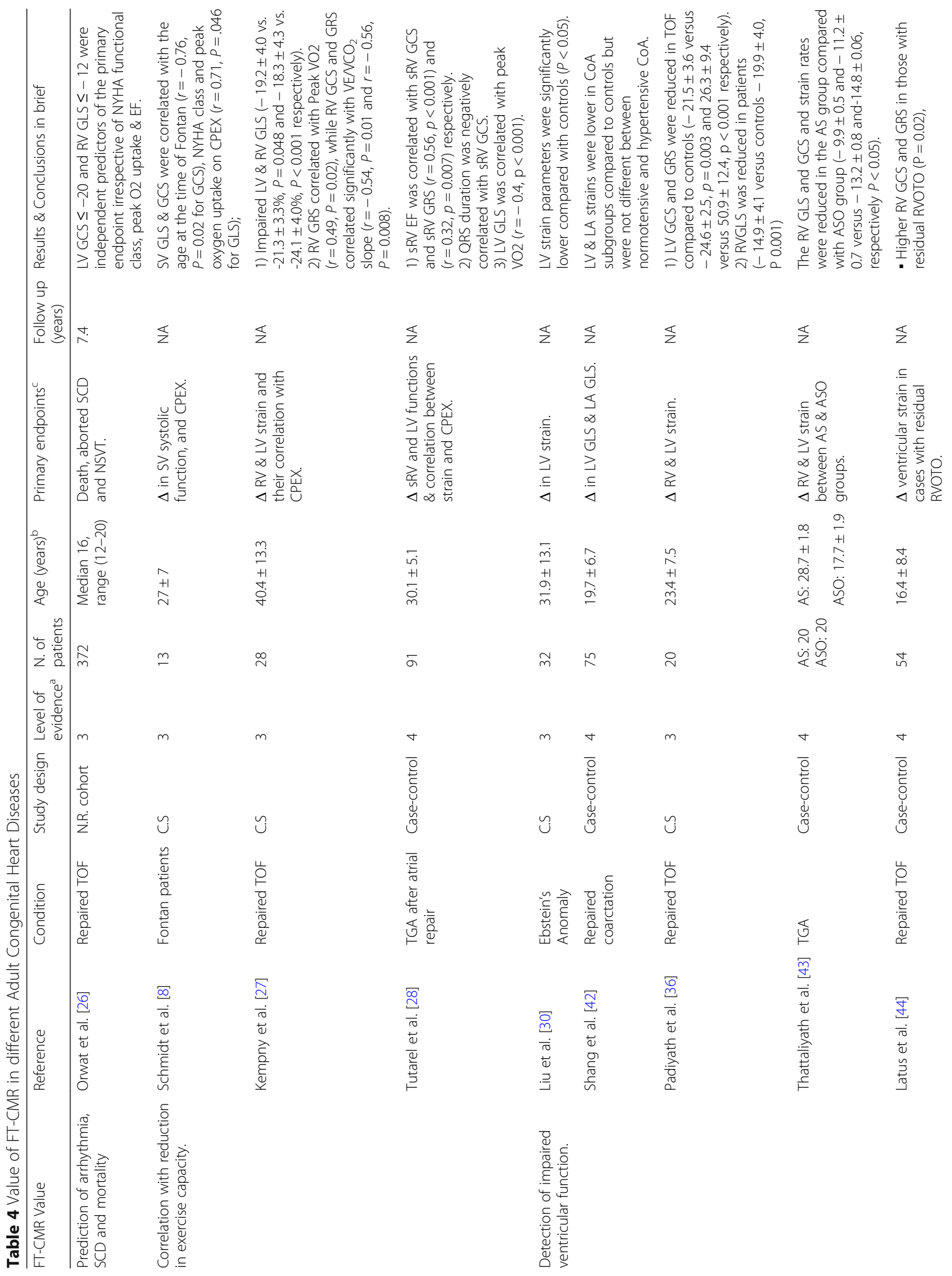




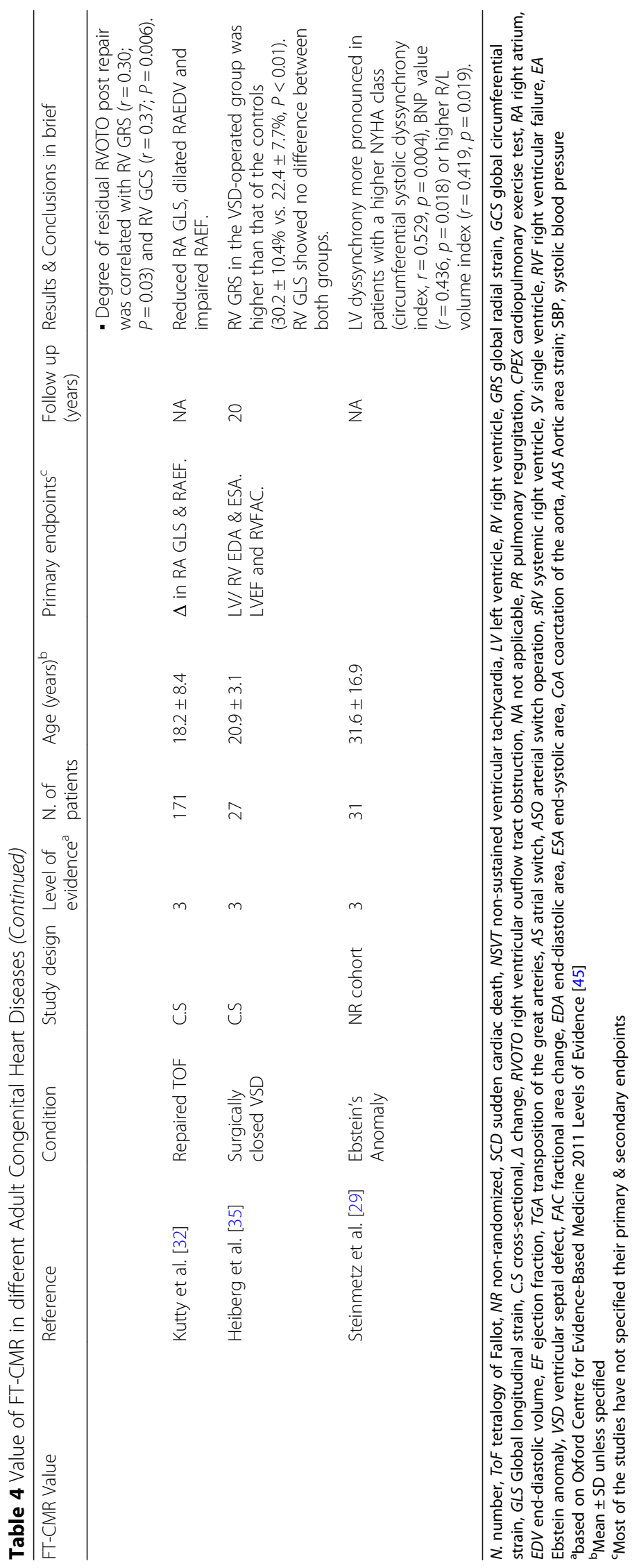


example, Steinmetz et al. [29] have recently investigated FT-CMR in 31 Ebstein patients (mean age 31.6 +/- 16.9 years) and 31 matched controls and found LV dyssynchrony which was more pronounced in patients with a higher NYHA class (circumferential systolic dyssynchrony index, $r=0.529, p=0.004)$, BNP value $(r=0.436, p=0.018)$ or higher $\mathrm{R} / \mathrm{L}$ volume index $(r=0.419, p=0.019)$. Liu et al. [30] also detected impaired LV GLS, GCS and GRS in Ebstein's patients compared to controls, that were thought may predict later onset systolic dysfunction.

\section{The future for FT-CMR in adult congenital heart disease?}

Although FT-CMR offers much potential, challenges remain. Much of the data relating to FT-CMR comes from smaller case-control or cohort studies and there is a need to define the additional value of this technique in predicting prognosis compared to other useful parameters. These studies ideally need to be performed in larger, longitudinal cohorts in which the incremental benefits of this technique can be demonstrated, particularly in relation to cost-efficacy. In addition to studies on prognosis, a major area in ACHD is the appropriate and timely selection of those patients suitable for treatment, for example in device therapy using indices such as the circumferential (CURE) and radial (RURE) uniformity ratio estimates based on myocardial strain [31]. The technique of FT-CMR is currently hampered by limitations due to the temporal resolution of SSFP cine imaging and by reduced reliability in the assessment of radial strain. 3D volumes have the potential to reduce these limitations, providing these can be delivered with sufficient resolution.

\section{Conclusion}

FT-CMR is a simple, fast method for measurement of myocardial deformation that offers promise for quantifying function of both ventricles and atria. Results are similar to other methods for quantifying deformation, although are most reliable when measuring displacement and strain, specifically LV GCS and GLS. Early studies of FT-CMR derived strain parameters correlate with prognosis and exercise capacity in some ACHD populations. FT-CMR derived strain parameters have further potential diagnostic and prognostic value in the adult congenital heart disease patient population and warrant further study. Early published data is largely based on relatively small selected groups of patients and long term prospective collaborative multi-centre follow up studies of the role of FT-CMR in ACHD patients are warranted.

\section{Additional files}

Additional file 1: LV FT-CMR in HLA. Horizontal long axis cine image illustrates the FT-CMR of the left ventricle. Myocardial points are displayed in yellow color. (AVI $1218 \mathrm{~kb}$ )

Additional file 2: LV FT-CMR in the SA. Left ventricle short axis cine image at the mid-ventricular level. Endocardial and epicardial boundaries points are displayed in red and green colors respectively. (AVI 1167 kb)

Additional file 3: RV FT-CMR in Ebstein's anomaly. Horizontal long axis cine image illustrates the FT-CMR of the functional right ventricle in a case of Ebstein's anomaly. Myocardial points are displayed in yellow color. (AVI 599 kb)

\section{Abbreviations}

2D: Two dimensional; 3D: Three dimensional; ACHD: Adult Congenital Heart Disease; CHD: Congenital heart disease; CMR: Cardiovascular magnetic resonance; CSPAMM: Complementary spatial modulation of magnetization; CURE: Circumferential uniformity ratio estimate; Cvi: Circle cardiovascular imaging; DCM: Dilated cardiomyopathy; D-TGA: Dextro-transposition of the great arteries; Ecc: Peak systolic circumferential strain; EF: Ejection fraction; Ell: Peak systolic longitudinal strain; Err: Peak systolic radial strain; FT: Feature tracking; GCS: Global circumferential strain; GLS: Global longitudinal strain; HARP: Tagged harmonic phase; HLA: Horizontal long axis; LOA: Limits of agreement; LV: Left ventricle; LVEDD: Left ventricular end diastolic dimension; NYHA: New York Heart Association; Rc: Concordance correlation coefficient; RURE: Radial uniformity ratio estimate; RV: Right ventricle; RVEDD: Right ventricular end diastolic dimension; SA: Short axis; SPAMM: Spatial modulation of magnetization; SR: Strain rate; SSFP: Steady State free precession; STE: Speckle tracking echo; SV: Single ventricle; TAPSE: Tricuspid annular plane systolic excursion; TOF: Tetralogy of fallot; VSD: Ventricular septal defect

\section{Acknowledgements}

We thank Dr. Shanat Baig and Dr. Manvir K Hayer for their comments and support.

\section{Authors' contributions}

The study was conceived by AD, LH, RS, PC and RW. AD performed the literature review and drafted the manuscript. RS and $\mathrm{LH}$ reviewed and modified the manuscript. PC reviewed the manuscript and added changes. RW helped in the physical background of the topic. All authors contributed to writing and reviewing of the final manuscript.

\section{Competing interests}

The authors declare that they have no competing interests.

\section{Publisher's Note}

Springer Nature remains neutral with regard to jurisdictional claims in published maps and institutional affiliations.

\section{Author details}

'Department of Cardiology, Queen Elizabeth Hospital, University Hospital Birmingham, Birmingham, UK. ${ }^{2}$ Institute of Cardiovascular Sciences, University of Birmingham, Birmingham, UK. ${ }^{3}$ Minia University, Minia, Egypt.

Received: 13 January 2018 Accepted: 4 April 2018

Published online: 10 May 2018

\section{References}

1. Kilner PJ, Geva T, Kaemmerer H, Trindade PT, Schwitter J, Webb GD. Recommendations for cardiovascular magnetic resonance in adults with congenital heart disease from the respective working groups of the European Society of Cardiology. Eur Heart J. 2010;31(7):794-805.

2. Geva T. Repaired tetralogy of Fallot: the roles of cardiovascular magnetic resonance in evaluating pathophysiology and for pulmonary valve replacement decision support. J Cardiovasc Magn Reson. 2011;13:9.

3. Kalam K, Otahal P, Marwick TH. Prognostic implications of global LV dysfunction: a systematic review and meta-analysis of global longitudinal strain and ejection fraction. Heart. 2014;100(21):1673-80. 
4. Saito M, Negishi K, Eskandari M, Huynh Q, Hawson J, Moore A, Koneru S, Foster S, Marwick TH. Association of left ventricular strain with 30-day mortality and readmission in patients with heart failure. J Am Soc Echocardiogr. 2015;28(6):652-66.

5. Schuster A, Hor KN, Kowallick JT, Beerbaum P, Kutty S. Cardiovascular magnetic resonance myocardial feature tracking: concepts and clinical applications. Circ Cardiovasc Imaging. 2016;9(4):e004077.

6. Pedrizzetti G, Claus P, Kilner PJ, Nagel E. Principles of cardiovascular magnetic resonance feature tracking and echocardiographic speckle tracking for informed clinical use. J Cardiovasc Magn Reson. 2016;18(1):51.

7. Obokata M, Nagata Y, Wu VC, Kado Y, Kurabayashi M, Otsuji Y, Takeuchi M. Direct comparison of cardiac magnetic resonance feature tracking and 2D/ 3D echocardiography speckle tracking for evaluation of global left ventricular strain. Eur Heart J Cardiovasc Imaging. 2016;17(5):525-32.

8. Schmidt R, Orwat S, Kempny A, Schuler P, Radke R, Kahr PC, Hellige A, Baumgartner H, Diller GP. Value of speckle-tracking echocardiography and MRI-based feature tracking analysis in adult patients after Fontan-type palliation. Congenit Heart Dis. 2014;9(5):397-406.

9. Scatteia A, Baritussio A, Bucciarelli-Ducci C. Strain imaging using cardiac magnetic resonance. Heart Fail Rev. 2017;22(4):465-76.

10. Yeon SB, Reichek N, Tallant BA, Lima JA, Calhoun LP, Clark NR, Hoffman EA, Ho KK, Axel L. Validation of in vivo myocardial strain measurement by magnetic resonance tagging with sonomicrometry. J Am Coll Cardiol. 2001;38(2):555-61.

11. Young AA, Axel L, Dougherty L, Bogen DK, Parenteau CS. Validation of tagging with MR imaging to estimate material deformation. Radiology. 1993;188(1):101-8

12. Voigt JU, Pedrizzetti G, Lysyansky P, Marwick TH, Houle H, Baumann R, Pedri S, Ito $Y$, Abe Y, Metz S, et al. Definitions for a common standard for 2D speckle tracking echocardiography: consensus document of the EACVI/ASE/ industry task force to standardize deformation imaging. J Am Soc Echocardiogr. 2015;28(2):183-93.

13. Liu B, Dardeer AM, Moody WE, Hayer MK, Baig S, Price AM, Leyva F, Edwards NC, Steeds RP. Reference ranges for three-dimensional feature tracking cardiac magnetic resonance: comparison with two-dimensional methodology and relevance of age and gender. Int J Cardiovasc Imaging. 2018;34(5):761-75.

14. Forsha D, Risum N, Kropf PA, Rajagopal S, Smith PB, Kanter RJ, Samad Z, Sogaard P, Barker P, Kisslo J. Right ventricular mechanics using a novel comprehensive three-view echocardiographic strain analysis in a normal population. J Am Soc Echocardiogr. 2014;27(4):413-22.

15. Moceri P, Bouvier P, Baudouy D, Dimopoulos K, Cerboni P, Wort SJ, Doyen D, Schouver ED, Gibelin P, Senior R, et al. Cardiac remodelling amongst adults with various aetiologies of pulmonary arterial hypertension including Eisenmenger syndrome-implications on survival and the role of right ventricular transverse strain. Eur Heart J Cardiovasc Imaging. 2017;18(11):1262-70.

16. Hor KN, Baumann R, Pedrizzetti G, Tonti G, Gottliebson WM, Taylor M, Benson DW, Mazur W. Magnetic resonance derived myocardial strain assessment using feature tracking. J Vis Exp. 2011;48:2356.

17. Hor KN, Gottliebson WM, Carson C, Wash E, Cnota J, Fleck R, Wansapura J, Klimeczek P, Al-Khalidi HR, Chung ES, et al. Comparison of magnetic resonance feature tracking for strain calculation with harmonic phase imaging analysis. JACC Cardiovasc Imaging. 2010;3(2):144-51.

18. Moody WE, Taylor RJ, Edwards NC, Chue CD, Umar F, Taylor TJ, Ferro CJ, Young AA, Townend JN, Leyva F, et al. Comparison of magnetic resonance feature tracking for systolic and diastolic strain and strain rate calculation with spatial modulation of magnetization imaging analysis. J Magn Reson Imaging. 2015;41(4):1000-12.

19. Schuster A, Stahnke VC, Unterberg-Buchwald C, Kowallick JT, Lamata P, Steinmetz M, Kutty S, Fasshauer M, Staab W, Sohns JM, et al. Cardiovascular magnetic resonance feature-tracking assessment of myocardial mechanics: Intervendor agreement and considerations regarding reproducibility. Clin Radiol. 2015;70(9):989-98.

20. Ghelani SJ, Harrild DM, Gauvreau K, Geva T, Rathod RH. Echocardiography and magnetic resonance imaging based strain analysis of functional single ventricles: a study of intra- and inter-modality reproducibility. Int J Cardiovasc Imaging. 2016;32(7):1113-20

21. Mulder BJ. Epidemiology of adult congenital heart disease: demographic variations worldwide. Neth Heart J. 2012;20(12):505-8.

22. Khairy P, lonescu-Ittu R, Mackie AS, Abrahamowicz M, Pilote L, Marelli AJ. Changing mortality in congenital heart disease. J Am Coll Cardiol. 2010; 56(14):1149-57.
23. Khairy P, Dore A, Poirier N, Marcotte F, Ibrahim R, Mongeon FP, Mercier LA. Risk stratification in surgically repaired tetralogy of Fallot. Expert Rev Cardiovasc Ther. 2009;7(7):755-62.

24. Ortega M, Triedman JK, Geva T, Harrild DM. Relation of left ventricular dyssynchrony measured by cardiac magnetic resonance tissue tracking in repaired tetralogy of fallot to ventricular tachycardia and death. Am J Cardiol. 2011;107(10):1535-40.

25. Moon TJ, Choueiter N, Geva T, Valente AM, Gauvreau K, Harrild DM. Relation of biventricular strain and dyssynchrony in repaired tetralogy of fallot measured by cardiac magnetic resonance to death and sustained ventricular tachycardia. Am J Cardiol. 2015;115(5):676-80.

26. Orwat S, Diller GP, Kempny A, Radke R, Peters B, Kuhne T, Boethig D, Gutberlet M, Dubowy KO, Beerbaum P, et al. Myocardial deformation parameters predict outcome in patients with repaired tetralogy of Fallot. Heart. 2016;102(3):209-15.

27. Kempny A, Fernandez-Jimenez R, Orwat S, Schuler P, Bunck AC, Maintz D, Baumgartner H, Diller GP. Quantification of biventricular myocardial function using cardiac magnetic resonance feature tracking, endocardial border delineation and echocardiographic speckle tracking in patients with repaired tetralogy of Fallot and healthy controls. J Cardiovasc Magn Reson. 2012;14:32.

28. Tutarel O, Orwat S, Radke RM, Westhoff-Bleck M, Vossler C, Schulke C, Baumgartner H, Bauersachs J, Rontgen P, Diller GP. Assessment of myocardial function using MRI-based feature tracking in adults after atrial repair of transposition of the great arteries: Reference values and clinical utility. Int J Cardiol. 2016;220:246-50.

29. Steinmetz M, Usenbenz S, Kowallick JT, Hosch O, Staab W, Lange T, Kutty S, Lotz J, Hasenfuss G, Paul T, et al. Left ventricular synchrony, torsion, and recoil mechanics in Ebstein's anomaly: insights from cardiovascular magnetic resonance. J Cardiovasc Magn Reson. 2017;19(1):101.

30. Liu X, Zhang Q, Yang ZG, Shi K, Xu HY, Xie LJ, Jiang L, Diao KY, Guo YK. Assessment of left ventricular deformation in patients with Ebstein's anomaly by cardiac magnetic resonance tissue tracking. Eur J Radiol. 2017;89:20-6.

31. Taylor RJ, Umar F, Moody WE, Meyyappan C, Stegemann B, Townend JN, Hor KN, Miszalski-Jamka T, Mazur W, Steeds RP, et al. Feature-tracking cardiovascular magnetic resonance as a novel technique for the assessment of mechanical dyssynchrony. Int J Cardiol. 2014;175(1):120-5.

32. Kutty S, Shang Q, Joseph N, Kowallick JT, Schuster A, Steinmetz M, Danford DA, Beerbaum P, Sarikouch S. Abnormal right atrial performance in repaired tetralogy of Fallot: a CMR feature tracking analysis. Int J Cardiol. 2017;248:136-42.

33. Liu B, Dardeer AM, Moody WE, Edwards NC, Hudsmith LE, Steeds RP. Normal values for myocardial deformation within the right heart measured by feature-tracking cardiovascular magnetic resonance imaging. Int J Cardiol. 2018;252(Supplement C):220-3.

34. Truong VT, Safdar KS, Kalra DK, Gao X, Ambach S, Taylor MD, Moore R, Taylor RJ, Germann J, Toro-Salazar O, et al. Cardiac magnetic resonance tissue tracking in right ventricle: feasibility and normal values. Magn Reson Imaging. 2017;38:189-95.

35. Heiberg J, Ringgaard S, Schmidt MR, Redington A, Hjortdal VE. Structural and functional alterations of the right ventricle are common in adults operated for ventricular septal defect as toddlers. Eur Heart J Cardiovasc Imaging. 2015;16(5):483-9.

36. Padiyath A, Gribben P, Abraham JR, Li L, Rangamani S, Schuster A, Danford DA, Pedrizzetti G, Kutty S. Echocardiography and cardiac magnetic resonancebased feature tracking in the assessment of myocardial mechanics in tetralogy of Fallot: an intermodality comparison. Echocardiogr. 2013;30(2):203-10.

37. Augustine D, Suttie JJ, Cox P, Lewandowski AJ, Holloway C, Petersen SE, Myerson S, Neubauer S, Leeson P. CMR right ventricular strain assessment using feature tracking cine images: agreement with echocardiography. J Cardiovasc Magn Reson. 2012;14(1):244.

38. Morton G, Schuster A, Jogiya R, Kutty S, Beerbaum P, Nagel E. Inter-study reproducibility of cardiovascular magnetic resonance myocardial feature tracking. J Cardiovasc Magn Reson. 2012;14:43.

39. Andre $F$, Steen $H$, Matheis $P$, Westkott M, Breuninger $K$, Sander $Y$, Kammerer $R$, Galuschky C, Giannitsis E, Korosoglou G, et al. Age- and gender-related normal left ventricular deformation assessed by cardiovascular magnetic resonance feature tracking. J Cardiovasc Magn Reson. 2015;17:25.

40. Augustine D, Lewandowski AJ, Lazdam M, Rai A, Francis J, Myerson S, Noble A, Becher H, Neubauer S, Petersen SE, et al. Global and regional left ventricular myocardial deformation measures by magnetic resonance feature tracking in healthy volunteers: comparison with tagging and relevance of gender. J Cardiovasc Magn Reson. 2013;15:8. 
41. Taylor RJ, Moody WE, Umar F, Edwards NC, Taylor TJ, Stegemann B, Townend JN, Hor KN, Steeds RP, Mazur W, et al. Myocardial strain measurement with feature-tracking cardiovascular magnetic resonance: normal values. Eur Heart J Cardiovasc Imaging. 2015;16(8):871-81.

42. Shang Q, Sarikouch S, Patel S, Schuster A, Steinmetz M, Ou P, Danford DA, Beerbaum P, Kutty S. Assessment of ventriculo-vascular properties in repaired coarctation using cardiac magnetic resonance-derived aortic, left atrial and left ventricular strain. Eur Radiol. 2017;27(1):167-77.

43. Thattaliyath BD, Forsha DE, Stewart C, Barker PC, Campbell MJ. Evaluation of Right Ventricular Myocardial Mechanics Using Velocity Vector Imaging of Cardiac MRI Cine Images in Transposition of the Great Arteries Following Atrial and Arterial Switch Operations. Congenit Heart Dis. 2015;10(4):371-9.

44. Latus H, Hachmann P, Gummel K, Khalil M, Yerebakan C, Bauer J, Schranz D, Apitz C. Impact of residual right ventricular outflow tract obstruction on biventricular strain and synchrony in patients after repair of tetralogy of Fallot: a cardiac magnetic resonance feature tracking study. Eur J Cardiothorac Surg. 2015;48(1):83-90.

45. OCEBM Levels of Evidence Working Group. "The Oxford 2011 Levels of Evidence" Oxford Centre for Evidence-Based Medicine. http://www.cebm.net/ index.aspx?o=5653. Accessed 06 Mar 2018.

Ready to submit your research? Choose BMC and benefit from:

- fast, convenient online submission

- thorough peer review by experienced researchers in your field

- rapid publication on acceptance

- support for research data, including large and complex data types

- gold Open Access which fosters wider collaboration and increased citations

- maximum visibility for your research: over $100 \mathrm{M}$ website views per year

At BMC, research is always in progress.

Learn more biomedcentral.com/submissions 